WADI, Yonissa Marmitt; OLINTO, Beatriz Anselmo; CASAGRANDE, Attiliana De Bona. Filantropia, privatização e reforma: cenários da assistência psiquiátrica no estado do Paraná. História, Ciências, Saúde - Manguinhos, Rio de Janeiro, v.22, n.4, out.-dez. 2015, p.1353-1371.

\title{
Resumo
}

\section{Filantropia, privatização e reforma: cenários da assistência psiquiátrica no estado do Paraná}

\section{Philanthropy, privatization, and reform: psychiatric assistance scenarios in the state of Paraná}

Yonissa Marmitt Wadi

Professora, Centro de Ciências Humanas e Sociais/ Universidade Estadual do Oeste do Paraná Rua da Faculdade, 645

85903-000 - Toledo - PR - Brasil yonissa@pq.cnpq.br

\section{Beatriz Anselmo Olinto}

Professora, Departamento de História, Programa de Pós-graduação em História/ Universidade Estadual do Centro-Oeste. Rua Salvatore Renna, 875 85015-430 - Guarapuava - PR - Brasil biaolinto@hotmail.com

\section{Attiliana De Bona Casagrande \\ Mestre em Sociologia Política. \\ Servidão Tomaz José Oliveira, 154 88060-427 - Florianópolis - SC - Brasil attiliana@hotmail.com}

$\mathrm{O}$ artigo discute as diferentes configurações da assistência psiquiátrica no Paraná, dos primeiros anos à contemporaneidade, considerando suas especificidades e relações com as políticas nacionais. A assistência iniciou-se em 1903, com a inauguração do Hospício Nossa Senhora da Luz, uma instituição filantrópica. Somente em 1954 o primeiro hospital público, o Hospital Colônia Adauto Botelho, começou a funcionar. Na década de 1960, a partir de convênios entre o governo estadual e hospitais privados para a instalação de leitos no interior, o processo de assistência psiquiátrica foi acelerado, assumindo uma perspectiva de privatização. Tal estratégia ensejou a configuração atual dessa assistência no estado, na qual o hospital especializado viceja, a despeito da existência de outros equipamentos preconizados pelas leis da reforma psiquiátrica.

Palavras-chave: assistência psiquiátrica; instituições; saúde mental; Paraná.

\section{Abstract}

The article discusses different psychiatric assistance arrangements in Paraná from the earliest years through today, taking into account the state's unique features and relations with national policies. This assistance was first provided in 1903, when the Hospício Nossa Senhora da Luz philanthropic asylum was founded. It was only in 1954 that Hospital Colonia Adauto Botelho, the state's first public hospital, began operations. In the 1960s, the Paraná government signed agreements with private hospitals for more beds in the interior, accelerating the provision of psychiatric assistance and fostering a privatization approach. This strategy led to the current situation in Paraná, where specialized hospitals are the rule, despite the existence of other facilities foreseen under the psychiatric reform legislation.

Keywords: psychiatric assistance; institutions; mental health; Paraná. 
A inauguração do Hospício Nossa Senhora da Luz, em 1903, abriu a institucionalização da assistência psiquiátrica no Paraná. O Hospício, uma instituição religiosa e filantrópica ligada à Santa Casa de Misericórdia, permaneceu isolado nesse tipo de assistência até a abertura do Sanatório Espírita Bom Retiro, em 1945. Foi somente em 1954, com a inauguração do Hospital Colônia Adauto Botelho, que o estado passou a contar com o seu único hospital público psiquiátrico até os dias de hoje.

A partir de meados da década de 1960, pode-se visualizar a aceleração do processo de assistência psiquiátrica no Paraná. Isso ocorreu, fundamentalmente, em razão do estabelecimento de convênios entre governos estaduais e hospitais privados, para a instalação de leitos no interior do estado. Essa foi uma estratégia adotada pelos governos brasileiros, pósgolpe civil-militar de 1964, tanto para o campo da saúde geral quanto para o da psiquiatria, ou seja, um amplo movimento de privatização da assistência - transformada em um bem de mercado -, ação amparada por instituições governamentais e recursos públicos.

Tal movimento ensejou a configuração atual da assistência psiquiátrica no Paraná, na qual o hospital especializado, mais ou menos modernizado, persiste como a estrutura principal, a despeito da existência de vários outros equipamentos assistenciais, preconizados pelas leis de reforma psiquiátrica federal e estadual. No ano de 2010 existiam no Paraná 18 instituições especializadas, concentrando $92 \%$ dos 3.248 leitos psiquiátricos então existentes, sendo 15 delas de natureza jurídica privada e caráter empresarial, três filantrópicas e apenas uma pública. Parte desses hospitais teve o número de leitos reduzidos, outros foram fechados e novos foram abertos, encerrando-se o ano de 2012 com vinte instituições especializadas e 3.208 leitos psiquiátricos em funcionamento no estado. Uma característica marcante desse processo foi a substituição parcial da clientela das instituições especializadas, ou seja, não mais majoritariamente os portadores de transtornos mentais em sentido estrito, mas cada vez mais usuários de álcool e outras drogas adultos e jovens ocupando os leitos outrora reservados aos primeiros. ${ }^{1}$

Neste artigo, discutimos esse processo considerando a configuração das políticas de assistência à saúde, instituídas pelo Estado brasileiro ao longo do século XX, bem como atentando para as especificidades dos cenários desenvolvidos no Paraná. O objetivo principal é compreender as articulações entre o Estado e outros grupos, que permitiram a construção de grandes estruturas hospitalares e sua manutenção até os anos recentes. Busca-se também perceber as estratégias de adaptação e de sobreposição dessas instituições de confinamento com as modulações setorizadas de controle, ou seja, perceber as articulações para a remodelação de aspectos da assistência em instituições disciplinares.

\section{A filantropia em ação: as primeiras instituições}

A maioria das instituições psiquiátricas paranaenses foi fundada entre as décadas de 1970 e 1980, como se visualiza no Gráfico 1. Nas décadas anteriores, desde o início do século XX, poucas foram inauguradas: o primeiro hospital data de 1903; o segundo, da década de 1940; outros dois, da década de 1950; e dois, da década de 1960. O mesmo ocorreu nos anos 1990, quando foi criada no estado a última instituição considerada pelos órgãos responsáveis estritamente especializada em psiquiatria. 


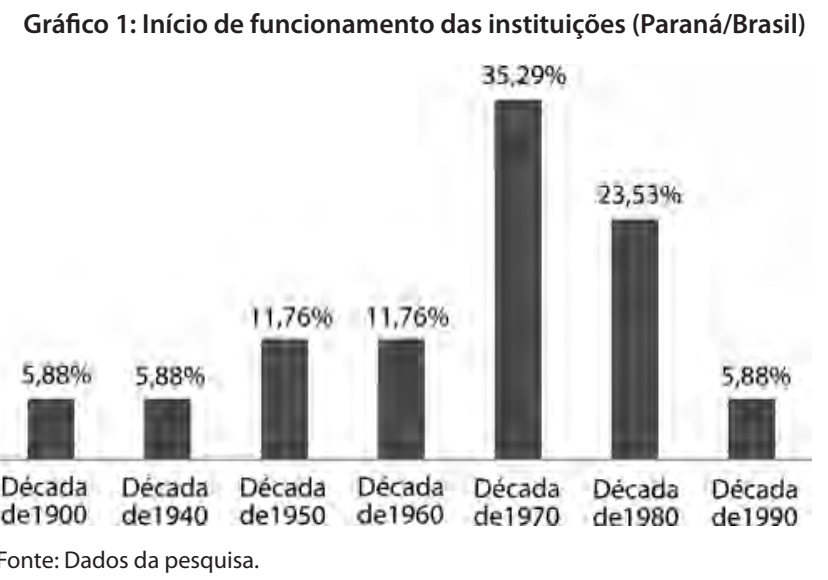

O Hospital Nossa Senhora da Luz, antigo Hospício Nossa Senhora da Luz, foi o primeiro hospital psiquiátrico do Paraná. Inaugurado em 25 de março de 1903, na capital, constituiuse a partir de um movimento organizado dentro da Santa Casa de Misericórdia, da mesma forma que outras instituições congêneres estabelecidas entre o final do século XIX e o início do XX. Argumentos de teor semelhante aos utilizados em outros lugares na mesma época, como a necessidade de criar um local com atendimento especializado para os alienados internados na Santa Casa de Misericórdia ou presos na cadeia da mesma cidade, justificaram sua construção (Ouyama, 2006; Wadi, 2002, 2009).

Segundo indicam mensagens dos governadores do estado e depoimentos de médicos atuantes nas décadas de 1940-1950 em cargos administrativos, após sua construção, "principalmente com fundos estaduais, houve certo relaxamento" (Fernandes Junior, 1987, p.61) por parte das autoridades em atender as reivindicações que vinham de distintos lugares sobre a necessidade do "recolhimento e da assistência aos alienados indigentes" (Paraná, 1951, p.126). Tais reivindicações ficavam "diluídas no grosso das inúmeras transformações necessárias aos serviços de saúde naqueles tempos" e o hospital ligado à Santa Casa por cerca de quarenta anos foi a única instituição de assistência psiquiátrica do Paraná (Fernandes Junior, 1987, p.61).

Apenas em 31 de março de 1945 foi inaugurado o segundo hospital psiquiátrico do estado, o Sanatório Bom Retiro, atual Hospital Espírita de Psiquiatria Bom Retiro, também localizado na capital. As tratativas da Federação Espírita do Paraná, visando à construção de um hospital, em que junto aos preceitos da ciência psiquiátrica desenvolver-se-iam as práticas espíritas de cuidados, iniciaram-se em 1920. Porém, dificuldades de caráter econômico paralisaram as obras em 1938, o que retardou a inauguração do hospital até 1945 (Sech citada em Wadi, 2009, p.80)

Porém, após a inauguração foram necessárias ainda gestões junto ao Ministério da Saúde para que a autorização de funcionamento fosse deferida, pois o médico indicado pela Federação Espírita para dirigir o hospital fora recusado pelo Ministério da Saúde, cujo Serviço Nacional de Doenças Mentais (SNDM) era dirigido pelo psiquiatra Adauto Botelho. ${ }^{2}$ Tratativas diversas para resolver o impasse foram encetadas pelos membros da federação, junto a figuras proeminentes da psiquiatria paranaense, como Arnaldo Gilberti, representante 
do Ministério no estado. Enfim, com a indicação para a direção do hospital do médico Alô Ticoulat Guimarães, catedrático de psiquiatria da Universidade Federal do Paraná, o hospital iniciou seu funcionamento em 25 de junho de 1946 (Sech, 15 out. 2009; FEP, s.d.; Lima, Holanda, 2011; Lima, 2011).

No caso das primeiras instituições psiquiátricas paranaenses, o exercício da filantropia, aliado à práticas religiosas e à terapêuticas advindas do campo médico-psiquiátrico, e a presença tênue ou mesmo ausência do Estado representam marcas comuns do processo de constituição, existência e atuação delas. Ambas foram projetadas e tornaram-se possíveis pela ação de grupos religiosos - católicos ou espíritas - aliados a grupos de leigos, eminentemente figuras de destaque na sociedade local.

Em relação ao Nossa Senhora da Luz, a figura de proa foi o monsenhor católico Alberto Gonçalves, provedor da Santa Casa de Misericórdia entre 1897 e 1908, que, além de circular em altos postos políticos - fora deputado provincial e senador federal -, era o elemento mais importante da instituição possuidora dos meios materiais para construir um hospício (Ouyama, 2006, p.268-275). No caso do hospital espírita, figuras de destaque no cenário da capital paranaense e membros da Federação Espírita do Paraná - como Flávio Ferreira da Luz, cartorário, ou Luiz Parigot de Souza, quartanista da Faculdade de Medicina -, envolvidos em polêmicas que visavam conter a reaproximação entre estado e Igreja católica na década de 1920, ou mesmo desvincular o espiritismo da sombra do charlatanismo, lideraram o movimento de sua criação (Lima, 2011).

Ao comparar a fundação dos dois hospitais, parece possível dizer em relação a essas instituições que, se a primeira recebeu atenção do estado, especialmente por meio da autorização para organização de loterias e subsídios para a construção da sede definitiva, pois supria a própria ausência de uma instituição conduzida pelo poder público, em uma época em que o Estado brasileiro - uma república recém-proclamada - tomava para si o controle e a gestão das instituições psiquiátricas (Ouyama, 2006; Wadi, 2002; Engel, 2001; Cunha, 1986); a segunda não parece ter contado com a mesma ajuda - pelo contrário, com uma fiscalização mais rigorosa (Lima, Holanda, 2011; Lima, 2011) - em um momento no qual o Estado já caminhara no sentido da centralização dessa assistência.

Por outro lado, não há registros nos relatórios governamentais do período sobre o efeito da inauguração do hospital espírita na resolução dos problemas da assistência psiquiátrica. No início da década de 1950, quando iniciadas as obras do primeiro hospital público com tal especialidade no Paraná, mensagens de governadores alertavam para o caos do atendimento no estado sem mencionar a contribuição do hospital espírita:

É simplesmente alarmante o número de doentes mentais que, sem recursos próprios para o necessário tratamento, são entregues à Polícia ou por ela capturada por constituírem uma permanente ameaça à segurança pública.

Não dispõe o Estado, enquanto não se concluírem as obras da Colônia de Psicopatas, de estabelecimento hospitalar capaz de atender à necessidade de internamentos de dementes indigentes. Uma instituição particular, o Hospital Psiquiátrico Nossa Senhora da Luz, é o que os vem recebendo, na medida da capacidade de suas instalações, devendo notar-se que esta de há muito foi ultrapassada. 


\begin{abstract}
No interior como na Capital não são em número reduzido os loucos de ambos os sexos que ficam recolhidos à cadeia, por prazo indeterminado, à espera de vaga no hospital; é confrangedor o espetáculo que oferecem essas pobres criaturas privadas da razão, na vizinhança e até muitas vezes na promiscuidade com delinquentes da pior espécie, completamente entregues a seu triste destino e sem receberem os cuidados médicos especializados que talvez os pudessem libertar de seus padecimentos e restituí-los ao convívio da sociedade (Paraná, 1951, p.126-127).
\end{abstract}

\title{
Hospital Colônia Adauto Botelho: uma instituição psiquiátrica pública
}

A mencionada "colônia de psicopatas" foi inaugurada em 5 de junho de 1954, em terreno distante $26 \mathrm{~km}$ da capital, atualmente localizado na cidade de Pinhais, e recebeu o nome de Hospital Colônia Adauto Botelho (HCAB), em homenagem ao então diretor do SNDM (Paraná, 1955). A inauguração desse hospital no estado apresenta-se como um dos resultados da política de assistência psiquiátrica brasileira gestada no primeiro período presidencial de Getúlio Vargas (1930-1945). Foi a partir de 1937, com o início do processo de reorganização da estrutura da saúde pública brasileira - a chamada reforma Capanema ${ }^{3}$ - e, especialmente entre os anos de 1941-1954, período em que Botelho dirigiu o SNDM, que tal política ganhou os contornos visualizados na implantação de uma série de serviços, setores e instituições, como o hospital mencionado, e que deveriam estar presentes em todo o país.

O desenvolvimento de uma política assistencial psiquiátrica pode ser considerado como parte do "planejamento e implantação de diretrizes modernizadoras de organização do próprio Estado" (Venancio, 2011, p.45), movimento que ganhou força no Estado Novo (1937-1945) e que, no âmbito da saúde, marcou também a adesão do governo brasileiro às diretrizes debatidas internacionalmente, sob os auspícios da Organização Pan-americana da Saúde, ou seja, centralização, coordenação e normalização das políticas pelo governo federal e descentralização das ações executivas (Lima, 2002, p.44-62; Lima, Fonseca, Hochmann, 2005, p.44; Venancio, 2011, p.44) A própria criação do SNDM, em 1941 - agregando a Divisão de Assistência a Psicopatas, de abrangência nacional e a Assistência a Psicopatas do Distrito Federal -, pode ser considerada como parte desse esforço: àquele serviço cabia a formulação e coordenação da política assistencial psiquiátrica de âmbito nacional; aos serviços ou divisões de assistência psiquiátrica dos estados, sua implantação efetiva (Venancio, 2011, p.45-46).

As diretrizes dessa política de assistência psiquiátrica podem ser visualizadas por meio do documento "Plano hospitalar psiquiátrico: sugestões para uma ação supletiva da União", apresentado pelo SNDM, possivelmente no mesmo ano de sua criação. O plano foi gestado a partir de um inquérito iniciado em 1937 pelo Departamento Nacional de Saúde, que avaliou as condições da assistência psiquiátrica no país e, em sua súmula do estado da assistência psiquiátrica oficial, o Paraná figurava - juntamente com os estados de Rio Grande do Sul, Pernambuco, São Paulo e Minas Gerais - entre aqueles que assistiam e tratavam os doentes mentais por métodos atualizados, fazendo a prevenção das psicopatias e realizando serviços sociais (Brasil, 1941, p.13). ${ }^{4}$

O primeiro diretor do HCAB foi o psiquiatra Arnaldo Gilberti, que, a convite do SNDM, viera ao Paraná anos antes para implantar uma rede de assistência psiquiátrica, o que resultou na fundação, em 1944, do primeiro ambulatório psiquiátrico de Curitiba, liderado por Gilberti. 
Em maio de 1946, o Departamento Estadual de Saúde fora elevado à categoria de Secretaria da Saúde e de Assistência Social, e no final da mesma década foi criado o Departamento Estadual de Higiene Mental e de Assistência a Psicopatas, com a justificativa de "prestar assistência psiquiátrica à população paranaense, quase que sem nenhum recurso disponível nesse ramo de atividades da saúde" (Fernandes Junior, 1987, p.61). Inserido nos ditames da política nacional de saúde e dos seus desdobramentos regionais, a construção do HCAB tornou-se, assim, naquele período histórico, a maior ação pública na área.

O estabelecimento de um novo hospital psiquiátrico era uma "velha aspiração paranaense" - enfatizou o governador Antonio Annibelli em sua mensagem à Assembleia Legislativa em 1955 (Paraná, 1955, p.125); uma necessidade urgente frente às "solicitações de internamentos ... cada vez mais frequentes, sem que o Estado dispusesse dos leitos hospitalares necessários à satisfação da demanda", segundo outra autoridade pública na época, o médico Jayme Drummond de Carvalho (citado em Fernandes Junior, 1987, p.61), primeiro diretor do Departamento Estadual de Higiene Mental e de Assitência a Psicopatas. Isso decorreria dos problemas causados pelo desordenado crescimento paranaense, sentidos especialmente em Curitiba e nas cidades centrais do norte novo (Londrina e Maringá), que rapidamente se urbanizavam.

\section{A privatização da assistência psiquiátrica}

Considerando a organização atual das instâncias administrativas da saúde do Paraná, os três hospitais mencionados estão localizados na jurisdição da $2^{a}$ Regional de Saúde (RS) Metropolitana (Curitiba), que congrega mais cinco instituições, ou seja, 44,44\% do total de hospitais especializados do estado. ${ }^{5}$ Os demais estão distribuídos entre outras sete regionais, com destaque para a $17^{\mathrm{a}} \mathrm{RS}$ - Londrina, que congrega quatro instituições, ou 22,22\%, como se pode visualizar na Tabela 1.

Na jurisdição do que constitui atualmente a $17^{\mathrm{a}}$ RS foi inaugurado em 1957 o quarto hospital psiquiátrico do Paraná, o Hospital Shangri-lá, atualmente Hospital Psiquiátrico de Londrina. ${ }^{6}$

\begin{tabular}{|c|c|}
\hline Regional de Saúde & Porcentagem (\%) \\
\hline 2a RS Metropolitana (Curitiba) & 44,44 \\
\hline 17a RS Londrina & 22,22 \\
\hline 6a RS União Vitória & 5,56 \\
\hline 14a RS Paranavaí & 5,56 \\
\hline 20a RS Toledo & 5,56 \\
\hline 15a RS Maringá & 5,56 \\
\hline 12a RS Umuarama & 5,56 \\
\hline 16a RS Apucarana & 5,56 \\
\hline Total & 100,00 \\
\hline
\end{tabular}

Fonte: Dados da pesquisa. 
Com a assistência psiquiátrica concentrada na capital, o atendimento da demanda do interior do estado era considerado pelos governantes precário e também oneroso. Nesse sentido, diferentes governadores aventaram soluções, fosse por meio da criação de grandes hospitais psiquiátricos no interior - como a construção de um hospital-colônia com mil leitos em Londrina, para "atendimento dos doentes da região, que hoje são obrigados a procurar tratamento em Curitiba", proposta que nunca se efetivou (Paraná, 1963, p.63-64; Paraná, 1966) - ou da ampliação da rede de ambulatórios. Em 1961, o então governador, Ney Aminthas de Barros Braga, anunciou que seria "estudada a instalação de dispensários para doentes mentais em Maringá, Londrina, Cornélio Procópio, Irati e Apucarana, visando atender no local aqueles que hoje precisam se deslocar para Curitiba" (Paraná, 1961, p.37-38). No ano seguinte, ele anunciou a criação e o início do funcionamento de Ambulatórios de Higiene Mental nas cidades de Maringá e Guarapuava (Paraná, 1962, p.71-72; Wadi, 2009).

As ações do governo estadual podem ter significado um movimento no sentido da inclusão dos municípios na gestão dos serviços de saúde pública, frente à centralização administrativa nas esferas estadual e federal, que marcara a organização destes nas décadas anteriores. A nova concepção de organização de tais serviços, perceptível pela instalação de ambulatórios de higiene mental e outros equipamentos sanitários em cidades do interior, pode ser considerada como parte do ideário do sanitarismo desenvolvimentista, que começou a ganhar força no segundo governo de Getúlio Vargas (1951-1954) e aprofundou-se no governo do presidente Juscelino Kubitschek (1956-1961). Tal corrente “defendia uma íntima relação entre desenvolvimento econômico e saúde; criticava a organização excessivamente verticalizada dos serviços de saúde pública, orientados por doenças; e atribuía ... importância destacada ao município na organização dos serviços de saúde" (Fonseca, 2010, p.146).

Porém, esse ideário não parece ter encontrado muita ressonância em termos de efetivas ações no Brasil como um todo, ou especificamente no Paraná, e o cenário da saúde no final dos anos 1950 foi marcado por crises. Primeiro, do sistema previdenciário, a qual desembocou nos anos 1960 em crise geral da estrutura do setor de saúde que acabou por desmontar o padrão anterior e fez emergir um novo, ou seja, aquele "presidido pelo princípio de capitalização da medicina" (Braga, Goes de Paula, 1981, p.84).

No Paraná, o processo de descentralização administrativa dos serviços de saúde, no que se refere à assistência psiquiátrica, não se efetivou plenamente, visto que a ideia da construção de um grande hospital-colônia em Londrina fracassou e a construção de ambulatórios cresceu em ritmo lento. O que ocorreu, especialmente a partir da instauração da ditadura civilmilitar em 1964 e consolidou-se nas décadas seguintes, foi o estabelecimento de convênios entre o governo estadual e hospitais privados para a instalação de leitos psiquiátricos no interior do estado. Já em 1966 foram realizados convênios com hospitais particulares para a instalação de seiscentos leitos em Londrina e dez em Ponta Grossa (Paraná, 1966, p.57).

O movimento ocorrido no Paraná estava em consonância com a estratégia adotada pelos governos militares, tanto para o campo da saúde geral quanto para o da assistência psiquiátrica, ou seja, um amplo movimento de privatização da assistência amparado por instituições governamentais - como o recém-criado Instituto Nacional de Previdência Social (INPS), em 1966 - e recursos públicos. Em contrapartida, os hospitais públicos tornaram-se "cada vez 
menos significativos em termos de atendimento. Algum tempo depois, praticamente todos os hospitais psiquiátricos, públicos ou privados, estavam conveniados" (Paulin, Turato, 2004, p.247). ${ }^{7}$

Tal processo de privatização da assistência entrou em marcha acelerada na década de 1960. Se entre 1941 e 1961 o crescimento tanto de hospitais públicos quanto de privados foi "vegetativo", só no triênio 1965-1968 a população hospitalar aumentou em 20\%, sendo $60 \%$ na rede particular. Desses $20 \%$, cerca de 51\% referem-se às primeiras admissões (84\% na particular) e $48 \%$ no total de readmissões ( $98 \%$ na rede particular). Além disso, houve "um crescimento de $45 \%$ no total de leitos-chão (1.040\% na particular)", configurando uma verdadeira "indústria da loucura" (Cerqueira citado em Paulin, Turato, 2004, p.247). Podese afirmar, assim, que no cenário brasileiro, não só no que se refere à assistência à loucura,

a prioridade conferida à medicina curativa, o financiamento público e o crescimento dos grupos privados no setor de saúde são as engrenagens de um processo em que a capitalização e expansão da rede privada, por um lado, e a degradação dos serviços públicos e a sangria dos recursos do Estado, por outro, são faces da mesma moeda (Almeida, Pêgo citado em Ponte, 2010, p.187, 189).

Mantendo um único hospital público - o HCAB -, pode-se visualizar na Tabela 2 a aceleração do processo de privatização no Paraná por meio da relação de hospitais e clínicas particulares fundados nas décadas de 1960 e 1970, em contraste com o longo período anterior no qual existiam apenas quatro hospitais psiquiátricos no estado.

Alguns dos hospitais relacionados na Tabela 2 foram abertos com poucas vagas, porém, rapidamente ampliaram seu atendimento, fundamentalmente em razão dos convênios firmados com o INPS. Um exemplo é o Hospital Psiquiátrico de Maringá, fundado em 1962,

Tabela 2: Hospitais psiquiátricos privados (Paraná, Brasil, décadas de 1960 e 1970)

\begin{tabular}{lll}
\hline Nome & Município & Ano \\
\hline Hospital Psiquiátrico de Maringá & Maringá & 1962 \\
Hospital Psiquiátrico Franco da Rocha & Ponta Grossa & 1967 \\
Hosíca Dr. Hélio Rotenberg & Curitiba & 1968 \\
Hospital Psiquiátrico Nosso Lar & Cascavel & 1970 \\
Casa de Saúde de Rolândia & Loanda & 1970 \\
Clínica Santa Cruz & Rolândia & 1970 \\
Clínica Heidelberg & Umuarama & 1970 \\
Hospital San Julian & Curitiba & 1972 \\
Hospital Psiquiátrico Filadélfia & Piraquara & $1975^{*}$ \\
\hline
\end{tabular}

Fonte: Dados da pesquisa, com base em Paraná (2007); Lendzion (2007).

* O hospital foi criado em 1968, mas iniciou seu funcionamento efetivamente em 1975. 
com o nome de Sanatório Maringá. O hospital abriu suas portas com cerca de vinte leitos, mas já no início da década 1970 a instituição promoveu ampliações e reformas em sua estrutura física, passando a oferecer 364 vagas e recebendo pessoas de todo o estado do Paraná e de outros estados brasileiros, tais como São Paulo, Mato Grosso e Santa Catarina (Wadi, 2012, p.52-53).

As justificativas para tal crescimento são semelhantes às utilizadas para o incremento de vagas em todos os hospitais fundados no período: a demanda reprimida. No caso de Maringá, ancora-se também na ideia de que a edificação do hospital ocorreu em um momento no qual a cidade apresentava acelerado crescimento populacional em razão de um processo de prosperidade, concretização do ideal desenvolvimentista em voga no país. Porém, deste despontavam os típicos problemas da vida moderna que acabavam por afetar a saúde mental das pessoas. A construção de novos equipamentos urbanos era vista como solução para tais problemas, e, assim, o hospital psiquiátrico - uma invenção não tão nova - apresentava-se como novidade para suprir a necessidade de tratamento de doentes mentais pobres que, antes de sua criação, buscavam apoio em albergues, estavam nas prisões ou vagavam pelas ruas, o que era impróprio para uma cidade "moderna" (Campos, 2004).

$\mathrm{O}$ argumento sobre a demanda reprimida aparece comumente colado a outro, enunciado com bastante frequência, especialmente no caso das instituições criadas no interior do estado, ou seja, as dificuldades de encaminhamento de doentes para a capital, onde estavam concentrados os hospitais especializados.

Esse é o caso do Hospital Psiquiátrico Nosso Lar, criado no município de Loanda em 1970, por iniciativa de um grupo vinculado ao Centro Espírita Nosso Lar. Segundo depoentes, com o objetivo de efetivar o compromisso da comunidade espírita com a caridade, fora criado um albergue em 1967, em um terreno doado por um membro dessa comunidade. Como não recebeu a demanda esperada, somada a falta de recursos do município para tratar "as pessoas com problemas mentais", que ram levadas à capital, o prefeito da cidade na época - um médico renomado no município - sugeriu a um dos fundadores que o albergue fosse transformado em hospital psiquiátrico. Assim, atender-se-ia, de um lado, a necessidade e, de outro, o desejo de realizar a caridade (Andreo, 8 out. 2008).

O estímulo à criação dessa instituição, vindo de uma autoridade pública, fundava-se no conhecimento da possibilidade concreta de acolhimento, por parte do Estado, da demanda de uma instituição privada, especialmente se esta tivesse um caráter filantrópico. Se não há condições claras, com a documentação disponível, de afirmar que isso efetivamente ocorreu em relação ao hospital espírita de Loanda, o cenário descrito para o período da criação desse hospital, como de todos os outros citados na Tabela 2, permite levantar tal hipótese.

Outro argumento para a criação de instituições psiquiátricas no Paraná, destacado por depoentes que muitas vezes estiveram capitaneando tal criação, foi o da precariedade do atendimento na única instituição pública do estado, o HCAB. O argumento serviu como justificativa, por exemplo, para a construção do Hospital San Julian, localizado na cidade de Piraquara, que começou a funcionar em 1975 com o nome de Hospital de Neuropsiquiatria do Paraná (Antoniuk, 23 set. 2009; Wadi, 2012).

Além dessas motivações, destacadas majoritariamente por depoentes ligados às administrações hospitalares e revestidas de um caráter humanitário - ou seja, visavam especialmente oferecer assistência a quem necessitava -, outros interesses motivadores para 
a criação de novas instituições sobressaem nos depoimentos. Destaca-se especialmente a afirmação de que era um bom empreendimento naquela conjuntura a construção de um hospital psiquiátrico, fosse a partir de uma estrutura especialmente pensada para esse fim ou por meio da transformação de estruturas já existentes para sua instalação, como ocorreu, em 1979, na readequação do Hospital Filadélfia, de Marechal Cândido Rondon, originariamente um hospital geral com maternidade (Seyboth, 10 jun. 2009; Araújo, 2011).

Tendo como base uma conjuntura política favorável à instalação de instituições privadas, mediante financiamento público e a quem caberia acolher tal demanda reprimida, configurouse o cenário atual da assistência psiquiátrica no Paraná em relação à natureza jurídica das instituições, como mostra o Gráfico 2. Ela permanece praticamente sem alterações até os dias de hoje.

Gráfico 2: Natureza jurídica das instituições psiquiátricas (Paraná, Brasil, 2010)

Dados sobre a distribuição dos leitos psiquiátricos nas cidades paranaenses em 2010, obtidos durante pesquisa de campo, mostram que eles estavam majoritariamente alocados em instituições privadas. No Gráfico 3 é possível distinguir a quantidade de leitos destinados aos usuários do Sistema Único de Saúde (SUS) e a quantidade de leitos destinados aos convênios ou aos particulares. Esses dados informados pelas instituições são semelhantes aos disponíveis no Cadastro Nacional de Estabelecimentos de Saúde (CNES) para o mesmo ano e muito próximos aos disponíveis no final do ano de 2012, indicando que, na maioria das instituições, os leitos subsidiados pelo SUS

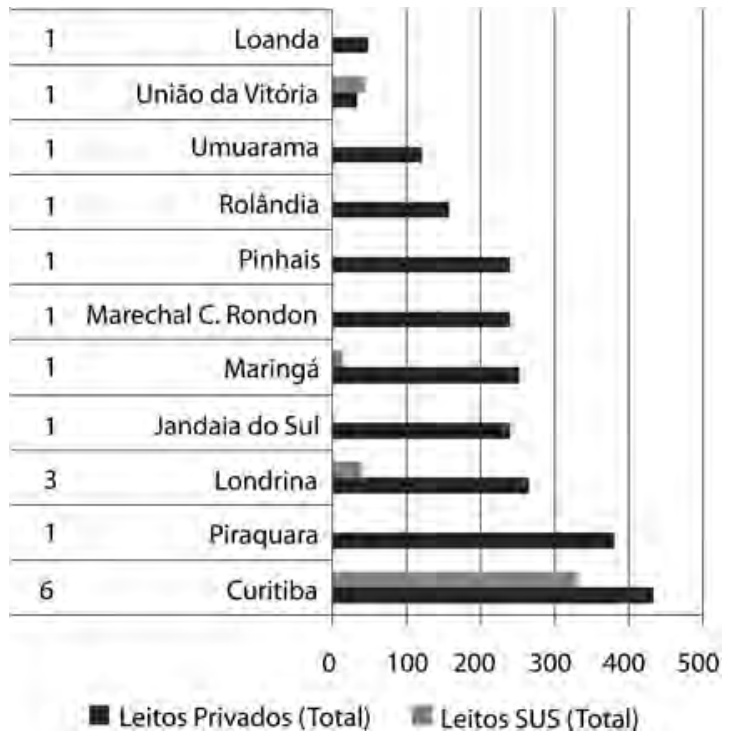

Fonte: Dados da pesquisa. constituem também a maioria de leitos disponíveis e que poucas instituições psiquiátricas não ofertam leitos desse tipo, estando três situadas em Curitiba e uma em Londrina (Brasil, 2012b; Wadi, 2012).

Gráfico 3: Quantidade de leitos SUS e não SUS por cidade (Paraná, Brasil, 2010)

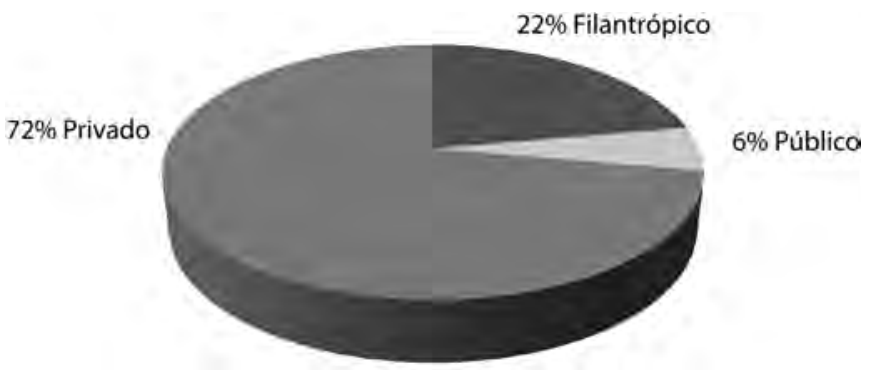

Fonte: Dados da pesquisa. 


\section{A reforma psiquiátrica: mudanças e permanências no cenário da assistência}

Antes da promulgação das leis da chamada reforma psiquiátrica, a assistência no estado do Paraná, bem como no restante do país, era restrita a alguns poucos leitos em hospitais gerais e às grandes unidades hospitalares especializadas. Os hospitais têm posição central na prestação de serviços de saúde no Brasil, pelo menos desde a década de 1950, tanto como local de atuação de uma especialidade - como as instituições manicomiais quanto como local de "encontro das diversas especialidades médicas, como detentor da infraestrutura e dos equipamentos necessários para a prestação dos serviços de saúde" (Braga, Goes de Paula, 1981, p.87).

O projeto de reforma psiquiátrica apresentado pelo então deputado federal Paulo Delgado (PT-MG), em 1989, pretendia alterar tal quadro ao propor "a extinção progressiva dos manicômios e sua substituição por outros recursos assistenciais", além da regulamentação da "internação psiquiátrica compulsória" (Brasil, 12 set. 1989). Com diversas modificações inseridas a partir de debates acirrados no Senado e na Câmara dos Deputados, a lei n.10.216 foi aprovada somente em 6 de abril de 2001, tendo como base o projeto original de Delgado e um projeto substitutivo do senador Sebastião Rocha (Partido Democrático Trabalhista/ Amapá), além de proposições incluídas por outros senadores. Tratando fundamentalmente dos direitos dos então chamados doentes mentais e de uma reorientação do modelo assistencial, sem excluir os hospitais psiquiátricos (Brasil, 2004), a lei "revogou a arcaica legislação de 1934, que ainda estava em vigor, e significou um avanço considerável no modelo assistencial" (Amarante, 2007, p.70).

O projeto de Delgado gerou um debate intenso sobre o tema no país e provocou, antes mesmo da aprovação da lei, mudanças no campo legal com a promulgação de várias portarias ministeriais. Essas portarias pretendiam normatizar as ações no território nacional: incentivando a criação de dispositivos novos e alternativos aos hospitais especializados, "tendo um serviço, o Centro de Atenção Psicossocial, como paradigma para a mudança" (Yasui, 2004, p.73); incidindo no controle dos hospitais psiquiátricos em funcionamento (fechamento ou readequação em razão do não cumprimento de condições mínimas estabelecidas pelo Ministério da Saúde); propondo uma nova sistemática de financiamento público. No longo período de tramitação da lei federal, vários estados, como Paraná, Rio Grande do Sul, Ceará, Pernambuco, Rio Grande do Norte, Minas Gerais, Espírito Santo e o Distrito Federal, além de diversos municípios, aprovaram leis de reforma, fazendo avançar o processo, que aos poucos foi incorporado pelo Estado, transformando-se na Política Nacional de Saúde Mental (Tenório, 2002; Amarante, 2007; Wadi, 2009; Yasui, 2004, 2010).

O Paraná posicionou-se entre os estados vanguardistas do processo de reforma psiquiátrica brasileiro, ao promulgar a lei estadual n.11.189, em 9 de novembro de 1995. Proposta pelo então deputado estadual Florisvaldo Fier (PT-PR) - conhecido por Doutor Rosinha -, a lei dispôs "sobre as condições para internações em hospitais psiquiátricos e estabelecimentos similares de cuidados com transtornos mentais", estabelecendo que ninguém com base em alegação de transtorno mental poderia ser limitado em sua condição de cidadão e sujeito de direitos, sofrendo internações ou quaisquer outras formas de privação de liberdade sem o devido processo legal (Brasil, 2004, p.53; Wadi, 2009, p.89). 
A lei definiu o novo modelo de atenção em saúde mental a ser erigido no Paraná, o qual deveria consistir na gradativa substituição do sistema hospitalocêntrico por uma rede integrada de variados serviços assistenciais de atenção sanitária e social. Por outro lado, condicionou a construção ou ampliação de hospitais psiquiátricos e a contratação e o financiamento de novos leitos a uma prévia aprovação pelo Conselho Estadual de Saúde, e ofereceu aos hospitais especializados, na medida da extinção de leitos psiquiátricos, a possibilidade de abertura de leitos em outras especialidades, a fim de propiciar sua transformação em hospitais gerais ou unidades de atenção à saúde mental (Brasil, 2004; Wadi, 2009).

Esses acontecimentos tiveram como fundamentos "uma crítica conjuntural ao subsistema nacional de saúde mental, mas também - e principalmente - uma crítica estrutural ao saber e às instituições psiquiátricas clássicas, dentro de toda a movimentação político-social que caracteriza a conjuntura de redemocratização" (Amarante, 1998, p.87). Foi especialmente na década de 1980 que contestações ao sistema de saúde governamental, no qual se inseriu o processo de crítica manicomial, ganharam força. Surgiram, assim, "propostas alternativas ao modelo oficial de atenção à saúde", enfatizando a necessidade de "democratização do sistema, com participação popular, a universalização dos serviços, a defesa do caráter público do sistema de saúde e a descentralização" (Escorel, Nascimento, Edler, 2008, p.73).

No bojo do processo de crítica e das modificações que surgiram - configuradas como programas e políticas públicas -, novas instituições, como hospitais-dia, Núcleos e Centros de Atenção Psicossocial (Naps e Caps), foram criadas em contextos mais diversos e em todas as regiões do país, além de haver maior disponibilização de leitos em hospitais gerais (Amarante, 1998; Tenório, 2002; Wadi, 2009). Porém, as grandes unidades ou instituições especializadas em psiquiatria respondem, ainda, no Paraná, bem como no restante do país, por parte significativa dessa assistência.

Ainda que mudanças significativas tenham ocorrido, dados disponíveis no CNES-Datasus mostram que existiam no Paraná 3.208 leitos psiquiátricos (SUS e particulares) no final do ano 2012. Desses, apenas 11,56\% estavam alocados em hospitais gerais, e o restante, $88,44 \%$, nas vinte instituições consideradas especializadas nesse ano. ${ }^{8}$ Por outro lado, a localização e a distribuição espacial dos leitos eram muito irregulares, pois cerca de $44 \%$ estavam alocados em instituições especializadas localizadas nas maiores cidades do Paraná, contrariando as normativas do Ministério da Saúde e as diretrizes da luta antimanicomial, como se pode observar a seguir: dos 759 leitos psiquiátricos disponíveis em Curitiba, 687 estavam alocados em quatro clínicas e dois hospitais especializados, e 72 estão distribuídos em sete hospitais e clínicas não especializadas; em Londrina, dos 350 leitos psiquiátricos, 345 eram ofertados em três clínicas psiquiátricas e cinco estavam disponíveis em um hospital não especializado; dos 304 leitos psiquiátricos disponíveis em Maringá, 272 eram ofertados em um hospital psiquiátrico e 32 em quatro hospitais gerais (Brasil, 2012b). ${ }^{9}$

Os dados indicam que o hospital especializado em psiquiatria persistia ainda em 2012, como instrumento preferencial de assistência às pessoas com sofrimento mental. Talvez não seja mais possível suspeitar que aquele continue a desenvolver um "papel 'insubstituível' de salvaguarda para o controle da 'periculosidade' e da 'cronicidade' psiquiátrica" (Venturini, 1995, p.14), pois assistimos ao espraiamento do novo modelo assistencial, que ultrapassa inclusive o universo psiquiátrico. Mudanças nas práticas terapêuticas desenvolvidas no 
interior das instituições especializadas, obedecendo às prerrogativas legais e à pressão social, também estão em andamento.

Atentando-se para a realidade do Paraná no ano de 2012, parece ainda válida a premissa de Tenório expressa em 2002 (p.54), ou seja, que "a atenção psicossocial comunitária ainda não é nem de longe a realidade hegemônica da rede", na medida em que no estado as chamadas estruturas comunitárias - Caps, residências terapêuticas, ambulatórios de saúde mental ainda estavam aquém do preconizado pelo Ministério da Saúde, apesar do grande avanço, especialmente no que diz respeito à implantação dos Caps.

Em 2012, o Paraná alcançou o índice recomendado pelo Ministério de um Caps ${ }^{10}$ para cada cem mil habitantes, contando então com 106 Caps, para uma população estimada em 2011 de 10.512.151 (Ipardes, 2011), ou seja, um para cada 99.171 habitantes. Nesse sentido, o Paraná encontrava-se entre os estados brasileiros com cobertura Caps para cada cem mil habitantes considerada muito boa (acima de 0,70), conforme mostra a Tabela 3, que cobre os anos de 2002 a 2011 (Brasil, 2012a).

Tabela 3: Indicador de cobertura Caps/cem mil habitantes por ano (Paraná, Brasil, 2002-2011)

\begin{tabular}{lllllllllll}
\hline UF & 2002 & 2003 & 2004 & 2005 & 2006 & 2007 & 2008 & 2009 & 2010 & 2011 \\
\hline PR & 0,15 & 0,16 & 0,21 & 0,28 & 0,45 & 0,60 & 0,65 & 0,67 & 0,72 & 0,76 \\
\hline
\end{tabular}

Fonte: Brasil (2012a, p.7).

Apesar do avanço na instalação dos Caps no Paraná, nas cidades maiores (como Curitiba, Londrina, Maringá, Foz do Iguaçu, Ponta Grossa e Cascavel), que concentravam tais equipamentos, eles não estavam plenamente de acordo com o coeficiente populacional preconizado. Todos os municípios citados tinham em 2012 população superior a 200 mil habitantes e, portanto, conforme a portaria n.336 do Ministério da Saúde (Brasil, 2004), deveriam possuir Caps III, Capsi (Infantil), Capsad (álcool e outras drogas), além do Caps II. Porém, naquele ano, exceto Londrina e Cascavel, não havia Caps III (equipamento que deve funcionar 24 horas) nos outros grandes municípios - nem mesmo a capital, com cerca de 1,8 milhão de habitantes (IBGE, 2012), possuía esse equipamento. Por outro lado, não havia Capsi Foz do Iguaçu, mas todos os cinco municípios, possuíam Capsad: Curitiba contando com quatro, e cada um dos outros municípios, com um (Brasil, 2012c).

Cerca de $80 \%$ dos municípios paranaenses têm dificuldades de acesso a tais equipamentos, pois seu nível populacional está abaixo do parâmetro mínimo estabelecido pelo Ministério da Saúde para implantar um Caps, ou seja, têm menos de 20 mil habitantes. Assim, na impossibilidade de obter serviços de base comunitária territorializados, a única alternativa para os habitantes de tais municípios que necessitem de assistência em decorrência de sofrimento mental é sua remoção para outras cidades e, não raro, sua internação nos hospitais especializados em psiquiatria, sem sequer transitar por quaisquer dos serviços de base comunitária (CRPPR, 2010; Brasil, 2004). ${ }^{11}$

Por outro lado, a implantação preferencial de Capsad em diversos municípios paranaenses, assim como a substituição dos leitos outrora destinados aos "transtornos mentais", em sentido estrito, por leitos para usuários de álcool e outras drogas, adultos e jovens, nos hospitais 
especializados, tem sido tendência crescente dos últimos anos. Se a primeira ação está de acordo com as diretrizes da reforma psiquiátrica, ou seja, implantar estruturas de atenção comunitária, de base extra-hospitalar, a segunda contradiz tais diretrizes. Isso ocorre na medida em que, seguindo as orientações do Plano Nacional de Avaliação do Sistema Hospitalar/ Psiquiatria (PNASH/Psiquiatria) e do Programa Anual de Reestruturação da Assistência Hospitalar Psiquiátrica no SUS (Fonte, 2011, p.4), os leitos para "transtornos mentais" em sentido estrito estão sendo fechados nas instituições especializadas paranaenses, mas em seu lugar - por vezes no número exato dos leitos fechados - tem sido implantados leitos para usuários de álcool e outras drogas. Essa é uma política do estado do Paraná, que mantém as estruturas hospitalares especializadas (segmentadas, fechadas) funcionando quase da mesma forma, mantendo, assim, vivo também o antigo paradigma médico-psiquiátrico, ainda que revisitado.

A percepção atual, compartilhada por parte da sociedade e do poder público, mas intensamente criticada pelo movimento antimanicomial, por grupos de direitos humanos, por profissionais da área - entre outros sujeitos sociais -, de que o uso do álcool, mas fundamentalmente das drogas ilícitas como o crack, deflagrou uma espécie de epidemia, tem sido uma das justificativas para a manutenção dessas estruturas como solução invertida da nova lógica que propôs a reforma psiquiátrica, expressa em uma legislação considerada avançada, baseada na existência de uma rede diversificada de serviços territoriais, capazes de permanentemente promover a integração social e assegurar os direitos dos seus usuários.

Se o Paraná, em termos da implantação de Caps, expandiu sua cobertura, isso não ocorreu em relação à implementação de outras das estruturas previstas e à sua distribuição pelas diversas regiões do estado. Pode-se tomar como exemplo os Serviços Residenciais Terapêuticos (SRTs), ${ }^{12}$ que, como mostra a Tabela 4, eram 22 em funcionamento e três em processo de implantação em 2011.

Tabela 4: Serviços Residenciais Terapêuticos, SRTs (Paraná, Brasil, 2011)

\begin{tabular}{lllll}
\hline UF & Módulos em funcionamento & Módulos em implantação & $\begin{array}{l}\text { Total de } \\
\text { módulos }\end{array}$ & Total de moradores \\
\hline PR & 22 & 03 & 25 & 138 \\
\hline
\end{tabular}

Fonte: Brasil (2012a, p.11).

Mesmo que as normativas governamentais indiquem a prioridade da implantação de SRTs em municípios onde já existam outros serviços ambulatoriais de saúde mental de natureza substitutiva aos hospitais psiquiátricos, percebe-se no Paraná que há uma concentração dessas estruturas nas grandes cidades e ausência na maioria dos municípios, mesmo nos que possuem outros serviços, conforme visualiza-se na Tabela 5.

Apesar da implantação de novos equipamentos e da redução de leitos em hospitais especializados, existem "distorções na garantia de acesso da população aos serviços", não possibilitando "a universalidade da atenção à saúde mental, princípio constitutivo do SUS, garantido pela Constituição Federal" (CRPPR, 2010, p.24; Mello, Viana, 2012). Repete-se o movimento de deslocamentos das pequenas cidades do interior para as cidades maiores e a falta de assistência às populações de parte substantiva do estado, questões que se constituíram em argumentos fortes outrora para a construção de grandes estruturas manicomiais. 
Tabela 5: Distribuição dos Serviços Residenciais Terapêuticos (SRTs) nos municípios (Paraná, Brasil, 2012)

\begin{tabular}{llc}
\hline Regional de Saúde & Município & Número de SRTs \\
\hline $2^{\text {a }} \mathrm{RS}$ & Curitiba & 5 \\
\hline $2^{\text {a RS }}$ & Quatro Barras & 3 \\
\hline $2^{\text {a RS }}$ & Campina Grande do Sul & 8 \\
\hline $10^{\text {a RS }}$ & Cascavel & 3 \\
\hline $15^{\text {a RS }}$ & Maringá & 3 \\
\hline Total & & 22 \\
\hline
\end{tabular}

Fonte: Paraná (2012).

\section{Considerações finais}

Não soa estranho que se escute o mesmo argumento - com nova roupagem - enunciado por administradores de muitas das instituições especializadas: se o Estado não cumpre com seu papel de implantar as estruturas ditas alternativas, como então reduzir leitos ou fechar as portas do hospital psiquiátrico? Tal realidade, ou seja, a disponibilização reduzida dos serviços de base comunitária, ou sua má distribuição no território, contribui, certamente, para a concentração dos leitos psiquiátricos nas instituições especializadas, em sua maioria privadas. Tal permanência aponta para uma sobreposição dos modelos de atendimento, lembrando a afirmação de Deleuze (2010, p.224) de que "na crise do hospital como meio de confinamento, a setorização, os hospitais-dia, o atendimento a domicílio puderam marcar de início novas liberdades, mas também passaram a integrar mecanismos de controle que rivalizavam com os mais duros confinamentos".

Afere-se, assim, que as demandas sociais de assistência instauradas após a reforma psiquiátrica adquiriram no Paraná uma configuração que pode lançar luz às opções de gestão em jogo no atendimento às pessoas com sofrimento mental na contemporaneidade. No estado em questão, a manutenção de uma aliança profilática público-privada garantiu que o atendimento em centros de apoio psicossocial fosse implantado mantendo o espaço para a permanência e readequação das instituições de isolamento do modelo hospitalocêntrico. Tal configuração foi e é possível mediante transferência de recursos públicos aos setores privados, em uma gestão de eficácia questionável para o atendimento da população.

\section{AGRADECIMENTOS}

Este trabalho apresenta resultados da pesquisa "Assistência psiquiátrica no estado do Paraná: mapeamento e análise histórica das instituições, da legislação e das principais políticas públicas", desenvolvida com apoio financeiro do Conselho Nacional de Desenvolvimento Científico e Tecnológico e da Fundação Araucária de Pesquisa do Paraná.

\section{NOTAS}

${ }^{1}$ O projeto de pesquisa, desenvolvido entre os anos 2007 e 2010, entre os vários cenários da assistência psiquiátrica no Paraná, investigou hospitais e clínicas especializados em psiquiatria. Conforme tipologia definida pela legislação vigente, visível nos sítios eletrônicos do Banco de Dados do Sistema Único de Saúde (Datasus) e da Secretaria da Saúde do Estado do Paraná (Sesa/PR), à época foram encontrados 18 hospitais e clínicas especializados em psiquiatria no estado. Os dados quantitativos apresentados no artigo foram obtidos na pesquisa, bem como por meio do CNES-Datasus, sempre que foram necessárias atualizações. 
${ }^{2}$ Adauto Botelho capitaneou a expansão da assistência psiquiátrica pelo Brasil, mediante o do SNDM, exercendo a função de diretor da instituição durante treze anos, de 1941 até o fim do segundo governo Vargas, logo após a morte do presidente em 1954. Sobre o SNDM e a atuação de Botelho frente a ele, ver Fabrício (2009, p.82-97) e Venancio (2011, p.45-46).

${ }^{3}$ Sobre a chamada reforma Capanema, ver Fonseca (2007, p.133-162).

${ }^{4}$ Essa observação é bastante curiosa porque, no momento da divulgação do plano, o estado do Paraná contava com uma estrutura pequena de atendimento, ou seja, apenas um hospital, como vimos. O plano oferecia, ainda, sugestões para ações a serem desenvolvidas pela união, tais como o auxílio técnico da Divisão de Assistência a Psicopatas aos estados para a elaboração de plantas de construção de instituições, que deveriam seguir um critério uniforme, conforme as técnicas assistenciais modernas e as possibilidades econômicofinanceiras dos próprios estados. O padrão sugerido pelo plano foi o de construções do tipo do hospitalcolônia, modalidade hospitalar considerada moderna na época, eficiente e menos dispendiosa (Brasil, 1941). A ideia de expandir os hospitais públicos, no molde do plano hospitalar, consolidou-se com o decreto-lei n.8.550, de 3 de janeiro de 1946, que autorizou o SNDM a realizar convênios com governos estaduais para a construção de hospitais psiquiátricos (Paulin, Turato, 2004, p.243). Tal planejamento materializou-se no Paraná já no ano seguinte, 1947, quando teve início a construção do hospital-colônia inaugurado em 1954 (Wadi, 2009, p.81, 2012, p.43).

${ }^{5}$ As regionais de saúde, em número de 22 no estado, constituem-se atualmente como instâncias administrativas intermediárias da Sesa. Cabe a elas assessorar, coordenar, gerenciar e dar apoio técnico no planejamento e execução de programas em saúde nos municípios paranaenses.

${ }^{6}$ As informações referentes ao hospital aqui apresentadas, inclusive a data pressuposta de sua fundação e seu nome original, foram obtidas mediante uma breve biografia de um de seus fundadores, o médico João Nicolau, disponível em: http://www.psiquiatrianet.com.br/. Acesso em: 30 jul. 2009.

${ }^{7}$ Ainda segundo os autores: "A situação deteriorada dos hospitais públicos levou ao 'discurso da competência', exposto pelos empresários privados. Valeria a pena investir em grandes hospitais públicos superlotados, inadequados, pouco terapêuticos e ineficazes para a cura dos doentes? Ou o caminho mais correto seria o pequeno hospital, com internação de curta duração, atendimento personalizado e possibilidade de reinserção social? Certamente, a opção pelo hospital privado era inerente a população previdenciária" (Paulin, Turato, 2004, p.247).

${ }^{8}$ O documento intitulado "Saúde mental no Paraná: a realidade da assistência em saúde mental no Paraná", da Sesa, indica a existência de apenas 15 hospitais psiquiátricos no estado, com 2.432 leitos, sem discriminar nomes, mas apresentando sua localização em mapa (Paraná, 2012). Por meio dessa localização é possível intuir quais as instituições identificadas no CNES-Datasus como instituições especializadas em psiquiatria que não constam do mapeamento da secretaria. Optou-se por manter as informações do CNES-Datasus como base analítica.

${ }^{9}$ A revista Contato (CRPPR, 2011, p.17) faz uma análise referente aos aspectos mencionados para o ano de 2010, também utilizando informações do CNES-Datasus, o que permite fazer a comparação com os números de 2012 e perceber a tênue mudança ocorrida.

${ }^{10}$ Conforme a legislação brasileira de saúde mental, os Caps são definidos como "unidades saúde localregionalizadas que contam com uma população adstrita definida pelo nível local e que oferecem atendimento de cuidados intermediários entre regime ambulatorial e internação hospitalar, em um ou dois turnos de quatro horas por equipe multiprofissional" (Brasil, 2004, p.12). Essas estruturas estão divididas em três níveis: Caps I e Caps II (para atendimento diário de adultos) e Caps III (para atendimento 24h, ou seja, diário e noturno de adultos), definidos por ordem crescente de porte, complexidade e abrangência populacional. Além desses são previstos os Capsi, destinados ao tratamento de crianças e adolescentes com transtornos mentais e os Capsad, destinados à população com transtornos mentais decorrentes do uso e dependência de substâncias psicoativas, como álcool e outras drogas. Uma descrição minuciosa das atribuições e especificidades dessas e outras estruturas comunitárias pode ser encontrada em Brasil (2004).

${ }^{11}$ Essa realidade foi verificada pela equipe do projeto em uma das etapas da pesquisa de campo realizada junto às regionais de Saúde do Paraná.

${ }^{12}$ Segundo a portaria n.3.090, de 23 de dezembro de 2011, do Ministério da Saúde, os SRTs acolhem pessoas com transtornos mentais e internação de longa permanência (dois anos ou mais ininterruptos), egressas de hospitais psiquiátricos e hospitais de custódia, de acordo com as diretrizes descritas na portaria n.106/ GM/MS, de 11 de fevereiro de 2000. Os SRTs configuram-se como dispositivo estratégico no processo de desinstitucionalização e caracterizam-se como moradias inseridas na comunidade. O caráter fundamental 
do SRT é ser um espaço de moradia que garanta o convívio social, a reabilitação psicossocial e o resgate de cidadania do sujeito, promovendo os laços afetivos, a reinserção no espaço da cidade e a reconstrução das referências familiares (Brasil, 23 dez. 2011).

\section{REFERÊNCIAS}

AMARANTE, Paulo (Coord.).

Loucos pela vida: a trajetória da reforma psiquiátrica no Brasil. Rio de Janeiro: Editora Fiocruz. 1998.

AMARANTE, Paulo.

Saúde mental e atenção psicossocial. Rio de Janeiro: Editora Fiocruz. 2007.

ANDREO, Pedro Leiva.

[Depoimento]. Entrevistadores: Karoline Vitorino da Silva de Paula e Jovane Gonçalves dos Santos. Loanda: Hospital Psiquiátrico Nosso Lar. 1 CD de áudio. 8 out. 2008 .

ANTONIUK, Affonso.

[Depoimento]. Entrevistadores: Yonissa Marmitt Wadi e Attiliana De Bona Casagrande. Curitiba.

1 CD de áudio. 23 set. 2009.

ARAÚJO, Franciele Aparecida de.

A loucura encontra seu lugar: um estudo sobre o processo de constituição da assistência psiquiátrica no Hospital Filadélfia de Marechal Cândido Rondon, Paraná. Dissertação (Mestrado em História) - Centro de Ciências Humanas, Educação e Letras, Universidade Estadual do Oeste do Paraná, Marechal Cândido Rondon. 2011.

BRAGA, José Carlos de Souza; GOES DE PAULA, Sérgio.

Saúde e previdência: estudos de política social. São Paulo: Cebes/Hucitec. 1981.

BRASIL.

Ministério da Saúde. Saúde Mental em Dados, ano 7, n.10. 2012a.

BRASIL.

Ministério da Saúde. CNES-Datasus. Relatório Indicadores - Leitos (Tipo de leito: psiquiatria). Disponível em: http://cnes.datasus.gov.br/. Acesso em: 11 dez. 2012. 2012b.

BRASIL.

Ministério da Saúde. CNES-D. Relatório

Indicadores - Tipo de estabelecimentos. Disponível em: http://cnes.datasus.gov.br/. Acesso em: 11 dez. 2012. 2012c.

BRASIL.

Ministério da Saúde. Portaria n.3.090. Disponível em: http://www.brasilsus.com.br/legislacoes/ gm/111278-3090.html. Acesso em: 9 jan. 2013. 23 dez. 2011.
BRASIL.

Ministério da Saúde. Legislação em saúde mental (1990-2004). Brasília: Ministério da Saúde. 2004.

BRASIL.

Câmara dos Deputados. Projeto de lei 3.657/1989. Disponível em: http:// www.camara.gov.br/ proposicoesWeb/fichadetramitacao?idProposic $\mathrm{ao}=20004$. Acesso em: 22 set. 2010. 12 set. 1989 .

BRASIL.

Ministério da Educação e Saúde. Departamento Nacional de Saúde. Plano hospitalar psiquiátrico: sugestões para a ação supletiva da União. Arquivo Gustavo Capanema; GCh 34.08.03, n.II14; mimeo (Centro de Pesquisa e Documentação de História Contemporânea do Brasil, Rio de Janeiro). 1941.

CAMPOS, Paulo Fernando de S. Os enfermos da razão: cidade planejada, exclusão e doença mental (Maringá, 1960-1980). São Paulo: Annablume; Fapesp. 2004.

CRPPR.

Conselho Regional de Psicologia do Paraná. Os leitos psiquiátricos no Paraná. Contato, ano 13, n.73, p.16-19. 2011.

CRPPR.

Conselho Regional de Psicologia do Paraná.

A estrutura no modelo substitutivo ao

hospitalocêntrico. Contato, ano 12, n.71, p.22-28. 2010.

CUNHA, Maria Clementina P.

O espelho do mundo: Juquery, a história de um asilo. Rio de Janeiro: Paz e Terra. 1986.

DELEUZE, Gilles.

Conversações. São Paulo: Editora 34. 2010.

ENGEL, Magali.

Os delírios da razão: médicos, loucos e hospícios (Rio de Janeiro, 1830-1930). Rio de Janeiro: Editora Fiocruz. 2001.

ESCOREL, Sarah; NASCIMENTO, Dilene Raimundo do; EDLER, Flávio Coelho. As origens da reforma sanitária e do SUS. In: Lima, Nísia Trindade et al. (Org.). Saúde e democracia: história e perspectivas do SUS. Rio de Janeiro: Editora Fiocruz. p.59-81. 2008.

FABRÍCIO, André Luiz da Conceição. A assistência psiquiátrica no contexto das políticas públicas de saúde (1930-1945). Dissertação (Mestrado em História das Ciências e da Saúde) - 
Casa de Oswaldo Cruz, Fundação Oswaldo Cruz, Rio de Janeiro. 2009.

FEP.

Federação Espírita do Paraná. Hospital Espírita Bom Retiro. Disponível em: http://www. feparana.com.br/histórico/espiritismo_parana02. htm. Acesso em: 23 set. 2008. s.d.

FERNANDES JUNIOR, Lindolfo Ribeiro. A Secretaria de Saúde do Paraná: suas origens e sua evolução no período de 1853-1983. Curitiba: Secretaria do Estado da Saúde do Paraná/ Fundação Caetano Munhoz da Rocha/Centro de Desenvolvimento de Recursos Humanos. 1987.

FONSECA, Cristina Maria Oliveira. Saúde pública no Governo Vargas. In: Ponte, Carlos Fidelis; Falleiros, Ialê (Org.). Na corda bamba de sombrinha: a saúde no fio da história. Rio de Janeiro: Casa de Oswaldo Cruz; Escola Politécnica de Saúde Joaquim Venâncio; Fiocruz. p.138-146. 2010.

FONSECA, Cristina Maria Oliveira.

Saúde no Governo Vargas (1930-1945): dualidade institucional de um bem público. Rio de Janeiro: Editora Fiocruz. 2007.

FONTE, Eliane Maria Monteiro da. A reforma psiquiátrica no Brasil e os desafios das novas práticas de cuidados na saúde mental. In: Congresso Luso Afro Brasileiro de Ciências Sociais, 15., 2011. Salvador. Anais... Salvador: Universidade Federal da Bahia. Disponível em: http://www.xiconlab.eventos.dype.com.br/ resources/anais/3/1307976792_ARQUIVO_ ArtConlab2011ElianeFonte.pdf. Acesso em: 3 mar. 2012. 2011.

IBGE.

Instituto Brasileiro de Geografia e Estatística. Estimativas de população para $1^{\circ}$ de julho de 2012. Disponível em: http://www.ibge.gov.br/ home/estatistica/ populacao/estimativa2012/. Acesso em: 20 dez. 2012. 2012.

IPARDES.

Instituto Paranaense de Desenvolvimento Econômico e Social. Caderno estatístico: estado do Paraná. Curitiba: Ipardes. 2011. Disponível em: http://www.ipardes.gov.br/cadernos/Montapdf. php?Municipio=00019. Acesso em: $20 \mathrm{dez} .2012$. 2011.

LENDZION, Kelli Cristine.

Vozes dissonantes: a reforma psiquiátrica em Ponta Grossa. Monografia (Bacharelado em História) - Setor de Ciências Humanas, Letras e Artes da Universidade Estadual de Ponta Grossa, Ponta Grossa. 2007.
LIMA, Andrea de Alvarenga.

Psiquiatria e espiritismo no atendimento à doença mental: a história do Hospital Espírita de Psiquiatria Bom Retiro (Curitiba, 19301950). Dissertação (Mestrado em Psicologia) - Departamento de Psicologia, Setor de Ciências Humanas, Letras e Artes, Universidade Federal do Paraná, Curitiba. 2011.

LIMA, Andrea de Alvarenga; HOLANDA, Adriano Furtado.

"O dr. Alô falou para não contrariar": a

consolidação da psiquiatria no Paraná na primeira metade do século XX. Revista Estudos e Pesquisa em Psicologia, v.11, n.1, p.353-368. 2011.

LIMA, Nísia Trindade.

O Brasil e a Organização Pan-Americana de Saúde: uma história em três dimensões. In: Finkelmann, Jacobo (Org.). Caminhos da saúde pública no Brasil. Rio de Janeiro: Organização Pan-americana de Saúde/Fiocruz. p.22-106. 2002.

LIMA, Nísia Trindade; FONSECA, Cristina Maria Oliveira; HOCHMANN, Gilberto.

A saúde na construção do Estado Nacional no Brasil: reforma sanitária em perspectiva histórica. In: Lima, Nísia Trindade et al. (Org.). Saúde e democracia: história e perspectivas do SUS. Rio de Janeiro: Editora Fiocruz. p.27-58. 2005.

MELLO, Guilherme Arantes; VIANA, Ana Luiza d'Ávila.

Uma história de conceitos na saúde pública: integralidade, coordenação, descentralização, regionalização e universalidade. História, Ciências, Saúde - Manguinhos, v.19, n.4, p.1219-1239. 2012.

OUYAMA, Maurício.

Uma máquina de curar: o hospício Nossa Senhora da Luz em Curitiba e a formação da tecnologia asilar (final do século XIX e início do século XX). Tese (Doutorado em História) - Setor de Ciências Humanas, Letras e Artes, Universidade Federal do Paraná. Curitiba: Universidade Federal do Paraná. 2006.

\section{PARANÁ.}

Secretaria de Estado da Saúde. Saúde mental no Paraná: a realidade da assistência em saúde mental no Paraná. Curitiba: Sesa. Disponível em: http://www.sesa.pr.gov.br/arquivos/File/ CIB/7aReuniao/Apresentacao_SM_Parana_ Nov2012.pdf. Acesso em: 15 jan. 2013. 2012.

\section{PARANÁ.}

Secretária de Estado da Saúde. Endereços da rede de atenção em saúde mental. Curitiba: Sesa/Isep/DSS/ Coordenação de Saúde Mental. Disponível em: http://200.189.113.52/saudemental/index.html. Acesso em: 1 jun. 2007. 2007. 
PARANÁ.

Assembleia Legislativa. Mensagem apresentada a Assembleia Legislativa do estado por ocasião da abertura da Sessão Legislativa Ordinária de 1966, pelo senhor Paulo Cruz Pimentel, governador do estado. Curitiba: Assembleia Legislativa do Paraná. 1966.

PARANÁ.

Assembleia Legislativa. Mensagem apresentada a Assembleia Legislativa do estado por ocasião da abertura da Sessão Legislativa Ordinária de 1963, pelo senhor Ney A. de Barros Braga, governador do estado. Curitiba: Assembleia Legislativa do Paraná. 1963.

PARANÁ.

Assembleia Legislativa. Mensagem apresentada a Assembleia Legislativa do estado por ocasião da abertura da Sessão Legislativa Ordinária de 1962, pelo senhor Ney A. de Barros Braga, governador do estado. Curitiba: Assembleia Legislativa do Paraná. 1962.

\section{PARANÁ.}

Assembleia Legislativa. Mensagem apresentada a Assembleia Legislativa do estado por ocasião da abertura da Sessão Legislativa Ordinária de 1961, pelo senhor Ney A. de Barros Braga, governador do estado. Curitiba: Assembleia Legislativa do Paraná. 1961.

\section{PARANÁ.}

Assembleia Legislativa. Mensagem apresentada a Assembleia Legislativa do estado por ocasião da abertura da primeira Sessão Legislativa Ordinária da oitava Legislatura 1955, pelo senhor Antonio Annibelli, governador do estado. Curitiba: Assembleia Legislativa do Paraná. 1955.

PARANÁ.

Assembleia Legislativa. Mensagem apresentada a Assembleia Legislativa do estado por ocasião da abertura da Sessão Legislativa Ordinária de 1951, pelo senhor Bento Munhoz da Rocha Neto, governador do estado. Curitiba: Assembleia Legislativa do Paraná. 1951.

PAULIN, Luiz Fernando; TURATO, Egberto Ribeiro.

Antecedentes da reforma psiquiátrica no Brasil. História, Ciências, Saúde - Manguinhos, v.11, n.2, p.241-258. 2004.

PONTE, Carlos Fidelis.

A saúde como mercadoria: um direito de poucos. In: Ponte, Carlos Fidelis; Falleiros, Ialê (Org.). Na corda bamba de sombrinha: a saúde no fio da história. Rio de Janeiro: Casa de Oswaldo Cruz; Escola Politécnica de Saúde Joaquim Venâncio; Fiocruz. p.187-193. 2010.
SECH, Maderli.

[Depoimento]. Entrevistadora: Attiliana De Bona Casagrande. Curitiba: Hospital Espírita de Psiquiatria Bom Retiro. $1 \mathrm{CD}$ de áudio. 15 out. 2009.

SEYBOTH, Carlos Mathias.

[Depoimento]. Entrevistadora: Franciele A. de Araújo. Marechal Cândido Rondon. 1 CD de áudio. 10 jun. 2009.

TENÓRIO, Fernando.

A reforma psiquiátrica brasileira, da década de 1980 aos dias atuais: história e conceitos. História, Ciências, Saúde - Manguinhos, v.9, n.1, p.25-29. 2002.

VENANCIO, Ana Teresa A.

Da colônia agrícola ao hospital-colônia:

configurações para a assistência psiquiátrica no Brasil na primeira metade do século XX. História, Ciências, Saúde-Manguinhos, v.18, supl.1, p.35-52. 2011.

VENTURINI, Ernesto.

Prefácio à primeira edição. In: Amarante, Paulo (Coord.). Loucos pela vida: a trajetória da reforma psiquiátrica no Brasil. Rio de Janeiro: Editora Fiocruz. p.15-16. 1995.

WADI, Yonissa Marmitt (Org.).

Instituições de assistência psiquiátrica do estado do Paraná: inventário. Guarapuava: Unicentro; Toledo: Edunioeste. 2012.

WADI, Yonissa Marmitt.

Uma história da loucura no tempo presente: os caminhos da assistência e da reforma psiquiátrica no estado do Paraná. Tempo e Argumento, v.1, n.1, p.68-98. 2009.

WADI, Yonissa Marmitt.

Palácio para guardar doidos: uma história das lutas pela construção do hospital de alienados e da psiquiatria no Rio Grande do Sul. Porto Alegre: Editora da UFRGS. 2002.

YASUI, Ś́lvio.

Rupturas e desencontros: desafios da reforma psiquiátrica brasileira. Rio de Janeiro: Editora Fiocruz. 2010.

YASUI, Sílvio.

De movimento social a política pública: conquistas e riscos da reforma psiquiátrica. Jornal Brasileiro de História da Medicina, v.7, supl.1, p.73. 2004. 